\title{
Transjugular Intrahepatic Portosystemic Shunt
}

National Cancer Institute

\section{Source}

National Cancer Institute. Transjugular Intrahepatic Portosystemic Shunt. NCI

Thesaurus. Code C126288.

An interventional radiologic procedure in which a shunt is created in the liver that

establishes communication between the portal vein and hepatic vein for the treatment of portal hypertension. The shunt is created using an image-guided endovascular approach, with the jugular vein as the entry site. 